REVIEW ARTICLE

https://doi.org/10.1057/s41599-019-0381-z

\title{
Collective efficacy: toward a new narrative of its development and role in achievement
}

\author{
T.J. Hoogsteen ${ }^{1 \star}$
}

\begin{abstract}
The body of collective teacher efficacy (CTE) research has developed considerably since Goddard referred to the school-level factor as a "neglected construct" in the study of schools and achievement. The research base has identified quantitative effects, antecedents, and consequences, all of which support the claim that collective efficacy is important to schools and achievement while also supporting the claim by Goddard et al. that schools should be led in a direction that will develop collective efficacy, which will in turn spur continuous growth in CTE and student achievement. Even with all of this, a gap in the literature remains, and instead of considering the reciprocal relationship between collective efficacy and achievement, the excitement behind the positive outcomes of collective efficacy has led to wider exposure of the concept and, as argued, a misguided attempt to treat CTE as the main catalyst for enacting school improvement. Considering this latter point, general school improvement literature from the realms of leadership and collaboration is drawn upon and connected to CTE research in an endeavor to create a more holistic narrative of collective efficacy, its development, and its role in school improvement and student achievement.
\end{abstract}

\section{Introduction}

ecently, two articles, one by Donohoo and Katz (2019) and the other by DeWitt (2019), titled "What drives collective efficacy" and "How collective teacher efficacy develops," respectively, touch on a popular topic in education research at the moment, collective teacher efficacy (CTE). Donohoo and Katz (2019) discuss the importance of mastery in the development of CTE, but the article views developing CTE as an end in itself and as an attribute to be developed to drive school improvement. The majority of the research and literature on the topic centers around the prevalent theory of action related to collective efficacy, that is, expectations influence efforts, and efforts influence achievement (Donohoo and Katz, 2017).

However, this article will undertake a review of literature and conceptual analysis in order to propose a new narrative of collective efficacy, re-evaluate the prevailing theory of action, and hypothesize a new one, hence moving the CTE knowledge base forward and creating opportunities for future research. The proposed depiction of the concept is one which regards school processes as being the most important factor in student success with collective efficacy being a by-product that, once produced, can stimulate further positive outcomes and improvement. This

\footnotetext{
${ }^{1}$ Independent Scholar, Cut Knife, SK, Canada. *email: tj.hoogsteen@lskysd.ca
} 
version of the development of collective efficacy can be represented as:

$$
\begin{gathered}
\text { Goal setting }+ \text { Collaboration }+ \text { Goal monitoring } \\
+ \text { Celebration }=\text { Mastery }=\text { Collective efficacy }
\end{gathered}
$$

As a concept, there are several ways CTE is defined; Goddard et al. (2000) characterized CTE as the perceptions of teachers in a school that the efforts of the faculty as a whole will have a positive effect on students (p. 480), whereas Tschannen-Moran and Barr (2004) classified it as the collective self-perception that teachers in a school make an educational difference to their students over and above the educational impact of their homes and communities (p. 190). These definitions emphasize the beliefs of teachers, which in most studies is usually measured through self-report Likert scale surveys such as those created by Goddard et al. (2000) and Tschannen-Moran and Barr (2004). The definitions align with the theory of action that beliefs result in action, which turn into results. Notions such as this have never been more apparent than in a recent publication by Donohoo and Katz (2017) titled "When teachers believe, students achieve".

Regardless of how CTE is defined, Donohoo (2017) stresses the importance of CTE by stating that because of its effect on student achievement it must not be understated or overlooked (p. 92). Quantitative studies seem to support this claim. In the first metaanalysis on the relationship between student achievement and CTE, Eells (2011) found CTE to have an average effect size of 0.617. Based on this research, John Hattie positioned CTE as the number one factor that influences student achievement. This claim places CTE above other well-known influences on achievement such as prior achievement and socioeconomic status. Hattie's updated effect size gives CTE an effect factor of 1.57 (Donohoo et al., 2018). CTE has also been noted as a predictor of differences in achievement between schools (Tschannen-Moran and Barr, 2004). Goddard (2001) found that CTE explained $47-50 \%$ of between-school variance in math and reading.

Although it has come a long way since Goddard (2001) referred to collective efficacy as a "neglected construct" in the study of schools and achievement, the research base on the topic is still developing. For example, Eells (2011) only included 26 relevant studies, many of which were conducted by researchers who had an affiliation with each other. A more recent literature review by Donohoo (2018) included only 34 studies related to CTE and achievement. Much of the literature that does exist focuses on antecedents, or how to develop collective efficacy, and benefits and effects of CTE.

Goddard et al. (2000) assert that schools should be led in a direction that will develop collective efficacy, which will in turn spur continuous growth in CTE and student achievement, and recently books such as that of DeWitt (2017) have placed a premium on the influence of CTE in leading schools. But as Planche (2019) notes, even though messaging about collective efficacy is hopeful, beliefs in collective abilities are not sufficient. What needs to be considered then is whether the evidence surrounding collective efficacy and its link to achievement has led, or may lead, to a rise of, as Eacott (2017) named it, the "cult of the guru". This phenomenon is a result of uncritical acceptance and proliferation of evidence and is possibly responsible for a misguided attempt to treat CTE as the main catalyst to drive school improvement efforts. This paper will examine this issue through a review of pertinent research on antecedents and consequences of collective efficacy. Then an alternative conceptualization with a more critical and holistic view of the link between achievement and CTE is proposed to move the literature base forward by taking into account bi-directionality of CTE as advanced in Donohoo (2018) or as Ross et al. (2004) referred to it, the reciprocal relationship between CTE and achievement.

\section{Developing CTE}

There are commonly accepted ways in which collective efficacy beliefs are developed. Arising from the work of Bandura (1997), and well acknowledged and accepted among other researchers in the field (Donohoo, 2017; Eells, 2011; Goddard et al., 2000; Tschannen-Moran and Barr, 2004), there four sources of collective efficacy. They are known as mastery experiences, vicarious experiences, social persuasion, and affective states. According to Bandura (1997), these sources are the same as those that develop self-efficacy, serve similar functions, and operate through similar processes. Adams and Forsyth (2006) attempted to have analysis of the teaching task (factors such as abilities and motivation of students and school resources) and assessment of teaching competence included as sources of efficacy, what they termed proximate sources of efficacy. However, most other work, such as Goddard et al. (2000), Goddard et al. (2004), and Eells (2011), view analysis of the teaching task and assessment of teaching competence as variables in the cognitive processing of efficacy information. If sources of efficacy are further alluded to, mastery experiences, vicarious experiences, social persuasion, and affective states will be what are intended. These efficacy belief-shaping sources are further influenced by school processes, such as leadership. A description of each source and influence on efficacy will follow.

Mastery experiences are often considered the most powerful source of CTE (Adams and Forsyth, 2006; Donohoo, 2017; Goddard, 2001; Goddard et al., 2004), although Ross et al. (2004) found evidence to dispute this claim (this will be expanded upon later). This type of experience usually results from actual successes of individual teachers and can act in concert at the individual and organizational level (Goddard et al. 2004). In fact, Goddard (2001) found that nearly two-thirds of between-school variation in collective efficacy was the result of differences in mastery experience (based on prior school achievement). While most published work seems to view mastery experience as noted above, Goddard et al. (2015) take a slightly different approach and reframe the source of efficacy as enactive experience, in other words, actually engaging in forms of work. Notwithstanding, according to Donohoo (2017), when teams experience success and causes for success are credited to be within the team's control, collective efficacy increases and expectations that results can be repeated are shaped.

A second source of efficacy are vicarious experiences. Goddard et al. (2004) explain that vicarious experiences are those in which a skill is modeled by someone else. When an observer sees a model perform well, the efficacy beliefs of the observer are enhanced; however, the converse is true as well. Bandura (1997) further suggested that vicarious experiences can be so strong that they can supersede direct experiences of failure and provide a model of future behavior even after repeated bouts of poor performance. Another interesting finding noted by Ross et al. (2004) pertaining to vicarious experiences is that, in schools, it is rare for teachers to be able to observe each other or teachers from other schools, so this source of efficacy is more likely to come from observations of how the success of teachers in the school contribute to the collective success of the faculty.

Social persuasion, the third source of collective efficacy, is another way by which teachers in a school can strengthen their conviction that they can achieve set goals (Goddard et al., 2004). In a school setting, social persuasion can take many forms, including feedback from a principal, superintendent, instructional coach, or discussions with peers during meetings (Eells, 2011). Verbal persuasion alone has limited power and depends on the credibility of the persuader; however, when coupled with mastery experience, it can influence the CTE of a school staff (Goddard et al. 2004). Although mastery experience has been shown to be 
the greatest source of collective efficacy, a study conducted by Beauchamp et al. (2014) showed that many teachers perceived social persuasion, for example, feedback from colleagues, to be a powerful influence on collective efficacy.

Affective states, also referred to as the "emotional tone of the organization" by Tschannen-Moran and Barr (2004) and "emotional and physiological cues" by Eells (2011), is the fourth and least influential of the sources of efficacy (Donohoo, 2017). Affective states can influence how schools interpret and react to the challenges they face. Just as individuals react to stress, so do organizations, thus levels of anxiety or excitement add to perceptions of capability or incompetence. For example, schools with high levels of CTE can handle pressure, such as those caused by standardized testing, and continue to function without adverse consequences (Goddard et al. 2004). Klassen (2010) found that, while high levels of CTE within a school did not lower stress from teacher workload, but CTE did partially mediate stress related to student behavior.

Besides the aforementioned sources of efficacy, school leadership also plays a role in the development of CTE. For example, Ross et al. (2004) noted several factors related to school processes and leadership that contributed to CTE. According to their findings, the processes with the strongest effects were shared school goals, school-wide collaboration, fit of plans with school needs, and empowering school leadership. Donohoo (2017) synthesized a list (which was very similar to the areas discussed above) of six enabling conditions. These were advanced teacher influence, goal consensus, teachers' knowledge about one another's work, cohesive staff, responsiveness of leadership, and effectiveness of intervention (p. 29).

Consequences of collective efficacy. For schools, the most important consequence of collective efficacy is its indirect influence on student achievement. This influence occurs from productive patterns of teaching behavior (Donohoo et al., 2018). Bandura (1997) noted that there are several attributes of efficacious schools. These attributes can be described as conveying high expectations to students, fostering learner autonomy, decreasing disruptive behavior, and increased parental involvement. He further notes that, while other aspects are often correlated with efficacious schools, they are not as replicable. However, Donohoo (2017) extended the list to include three more productive behaviors that contribute to the impact of CTE. She added putting forth greater effort and persistence, trying new teaching approaches based on effective pedagogy, and increased commitment. A short review of each consequence will be undertaken below.

Putting forth greater effort and persistence. One outcome associated with CTE is the effort and persistence of teachers in their classrooms. For example, Goddard et al. (2000) found that collective efficacy beliefs influence the level of effort and persistence teachers put forth in their daily work. Tschannen-Moran and Barr (2004) furthered this argument by noting that, in schools where collective efficacy is high, teachers exhibit persistence and resiliency when working with students who are having difficulty. In addition, Bandura (1997) claims that, even when below-standard performance occurs, dissatisfaction with said performance plus a strong sense of collective efficacy will spur group productivity.

New teaching approaches. When collective efficacy is high, teachers are more willing to try new teaching approaches based on effective practice and more cooperative of change efforts (Donohoo, 2017). Whereas low efficacious schools spend less time actively teaching, the opposite is true for schools where efficacy is high, and remediation for students who are struggling is meant to accelerate learning so that they can catch up to their peers (Bandura, 1997). Tschannen-Moran and Barr (2004) also note that mastery instructional approaches are more often used in highly efficacious schools. More mastery experiences in turn, according to Donohoo (2017), build students with high academic efficacy.

High expectations. Schools that have high collective efficacy, in turn, have high expectations and standards for achievement and these permeate the school environment (Bandura, 1997). In contrast, teachers who have a lower sense of efficacy set lower performance expectations (Tschannen-Moran and Barr, 2004) and students who are already struggling will continue to do so if they are taught by teachers with weak efficacy beliefs (Bandura, 1997). Donohoo (2017) asserts that the opposite is true as well, efficacious teachers set challenging and appropriate goals. But, as Bandura (1997) contends, high standards will not accomplish much if they are not coupled with instruction and learning activities (such as the mastery approaches alluded to in the previous section).

Fostering learner autonomy. Bandura (1997) asserts that efficacious schools distinguish themselves from lower efficacious schools through the structure of learning activities. Schools with high CTE promote a sense of personal capability in all students. These schools generally favor mastery models of learning, monitor progress closely, and provide feedback and re-instruction for those who encounter difficulty (p. 247). Donohoo (2017) further states that high-collective efficacy schools value a studentcentered teaching approach and encourage student autonomy, this in turn promotes intrinsic motivation of students (p. 23).

Decreasing disruptive behavior. In schools that are efficacious, classroom management is a successful endeavor. This is achieved through promoting, recognizing, and praising desired behavior rather than punishing disruptive behavior (Bandura, 1997). CTE influences how teachers collectively respond to misbehavior and staffs are more likely to persist in efforts to prevent and manage poor behavior. Furthermore, teachers are less discouraged and feel less stressed by temporary setbacks resulting for student misbehavior (Donohoo, 2017). Klassen (2010) presented a similar finding and observed that collective efficacy mediated the effects of student behavior on job-related stress.

Increased commitment. Commitment by teachers to students and the organization as a whole is integral to a school's success in improving student achievement and successful teaching. Furthermore, this commitment is significantly related to influence teachers have in decision making at the school level (Donohoo, 2017). Devos et al. (2014) demonstrated the same findings in their quantitative analysis of teacher commitment and participative decision making. As it relates to efficacy, increased commitment and willingness to exert effort on behalf of the organization is correlated with high levels of CTE (Donohoo, 2017).

Increased parental involvement. Bandura (1997) notes that a child's family plays a key role in their success in school (p. 245) and Hattie (2009) confirms this, as he ranks parental involvement among the biggest achievement contributions related to the home with an effect size of 0.49 . In turn, teacher's sense of efficacy has an effect on parental participation in their child's school. Teachers who have a healthy sense of efficacy are more likely to invite and support parents' educational efforts (Bandura, 1997; Ross and Gray, 2006). While increased parental involvement creates greater 
risk and opens teachers to criticism (Bandura, 1997), Ross and Gray (2006) explain that a staff with greater CTE can overcome obstacles of this nature.

\section{The argument against "building collective efficacy"}

Sources and the effects of efficacy as discussed are well documented and supported in the research base, and it is not the intention of this article to challenge these ideas or their value to schools and education, although criticisms do exist. Just as the theory of action have been uncritically accepted, so too have the sources and effects of efficacy. However, this analysis is questioning the prevailing theory of action that expectations influence efforts, and efforts influence achievement (Donohoo and Katz, 2017). The reason for this is that there appears to be a gap in the research resulting from a focus on sources of efficacy and effects (and developing such). Furthermore, while Ross et al. (2004) discusses school processes and their relationship to CTE, it does not appear to delve into the reciprocal nature of the school process/achievement/CTE relationship and how they interact with each other. For example, Fig. 1 (below) presents a commonly used model to describe the development and effects of collective efficacy in schools.

Figure 1 illustrates the development of CTE from the starting point of the four sources of efficacy without acknowledging how collective efficacy sources are employed in schools and how efficacy in turn is affected by and interacts with school processes. This absence has led to the belief that schools should focus on efficacy building to improve schools instead of creating the structures known to be a factor in successful schools. The argument of this paper and proposed theory of action is that, by concentrating on school processes known to affect achievement, schools will increase achievement thus building collective efficacy that can then promote future improvement. This argument differs from what is currently in the literature as it views CTE as a by-product or effect of successful school interactions rather than a precursor. The next section attempts to bridge the gap in the literature by presenting a new theoretical model of the development of collective efficacy in order to change the narrative that dominates the conversation of CTE and move the literature base forward by pushing school processes to the forefront of the conversation when considering the role of CTE on school improvement and achievement.

\section{Toward a new narrative of CTE}

This proposed narrative of collective efficacy is based on findings from the CTE knowledge base as well as the general leadership and school improvement literature. The first assumption being made, as Leithwood et al. (2010) contend, is that school leaders are capable of having positive effects on student learning and leadership has its greatest effects through dimensions such as (but not limited to) goal setting and supporting collaboration (Leithwood et al., 2012), and as Ross et al. (2004) state, school processes are the strongest predictor of CTE. Second is that mastery experience in the form of prior achievement is a powerful source of efficacy (Goddard, 2001) combined with a premise derived from Hallinger (2010) that, regardless of initial achievement, learning outcomes can be improved, and actually gain momentum, through changing key organizational processes. In the sections that follow, an explanation of these school processes and their interactions with CTE is offered.

\section{Leadership and goal setting}

According to Robinson (2011), goal setting has a moderate impact on student learning and can reduce fragmentation and promote coherence. This aspect of leadership works indirectly by focusing the work of adults around promoting learning and achievement of students. In fact, Schmoker (1999) notes that there is not a single instance in the literature where student learning improved where it was not the central goal. By itself, setting goals is not enough, the impact of goals is created by procuring acceptance of and commitment to the goals. This is accomplished through articulating the gap between current and desired performance and collective discussion and considering alternative opinions and possibilities (Robinson, 2011). Following the establishment of goals, progress can be monitored and goalbased data can reveal progress that motivates and sustains efforts (Schmoker, 1999). Fullan (2005) furthers this sentiment by claiming that short-term results are required to build confidence and gain the needed investment to move toward longerterm goals.

Goals are important to the discussion of CTE, and according to Schmoker (1999), goals not only lead to success but also effectiveness and cohesion of a team. Cohesion and collective influence are likely to be higher in schools in which teachers share a common vision and goals about the directions of the school (Ross et al., 2004). Goddard et al. (2015) notes that principal leadership is strongly correlated with creating the conditions for such

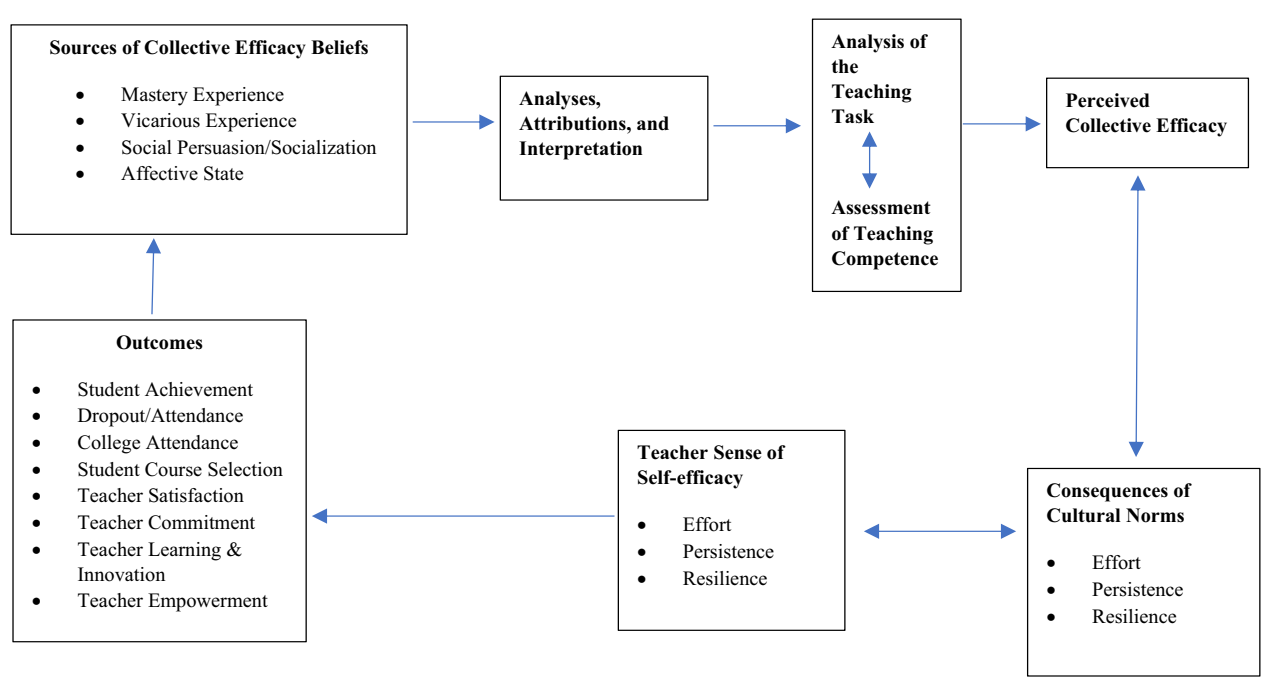

Fig. 1 Proposed model of the formation, influence, and change of perceived collective efficacy in schools (Goddard et al. 2004, p. 11). 
processes, and Ross et al. (2004) adds that when school leadership enacts a supportive approach in the area of goal setting there is potential to contribute to the sources of efficacy and this may be a stronger indicator of CTE than even mastery experiences.

However, for goals to contribute to sources of efficacy, progress on goals needs to be monitored. When goals are monitored through such processes as team meetings to analyze student data and progress is found, this leads to mastery experiences and thus greater beliefs that more success can be attained, even if such experiences were not present before. Mastery needs to be experienced prior to beliefs being developed in order for the collective beliefs to stimulate further progress. Ross et al. (2004) notes that leadership can influence teachers' interpretations of achievement as mastery; this can be accomplished through setting the conditions for data analysis meetings and interpreting data with teachers. Furthermore, Escobedo (2012) suggests that teacher celebrations and student celebrations should have a positive effect of collective efficacy beliefs, with teacher celebrations having a slightly greater effect. Celebrations of this nature can include recognition of successes at staff meetings and sharing of student success at school-wide assemblies. If the celebrations are meant to honor achievements, they should contribute to beliefs of mastery.

Escobedo (2012) argued that school celebrations contributed to vicarious sources of efficacy by providing a similar model of success for other teachers in the school. While this may be true, I would argue that success, even short-term results, is evidence of mastery and contributes to CTE as a source of mastery as well, even if every teacher did not experience success considering collective efficacy is an attribute based on whole-school perceptions. In sum, school leaders contribute to improved student outcomes by collaboratively setting school goals with teachers, monitoring and assessing goals often, and sharing and celebrating success. This success contributes to mastery and vicarious sources of efficacy, which in turn, can spur further improvement and outcomes associated with CTE.

\section{Leadership and collaboration}

According to Leithwood et al. (2012), there are four categories of core leadership practices that are effective across contexts, one of which is the aforementioned dimension of goal setting, and another is known as refining and aligning the school organization. Within this category is the specific practice of creating structures and opportunities for teachers to collaborate. Included in this study attempting to link leadership to student learning was a survey of principal and teachers. Over $90 \%$ of principals and almost $67 \%$ of teachers agreed that principals need to support collaboration through embedding time in the schedule for teachers to meet and discuss how they are working through curriculum (p. 59-62). This finding was very similar to the notion by Goddard et al. (2015) that some of the most powerful actions principals can take to support development of efficacy beliefs is to provide frequent, structured time for collaboration to form common understanding of good student work and supporting teachers' observations of each other's classrooms.

Goddard et al. (2015) further noted that school leaders who work toward instructional improvement through their support of teachers' collective work affected reports of collective efficacy beliefs in their schools. Insofar as collaboration is important, collective work needs to be related to common goals. As Schmoker (1999) states, without goals, teachers are not able to communicate meaningfully and precisely about how to determine if they are improving and action planning toward next steps (p. 25). Similarly, Ross et al. (2004) posited that collaboration contributed to teachers' knowledge of their classroom performance through common identification of indicators of student performance. Furthermore, teachers who interact with their colleagues may acquire teaching strategies that enhance effectiveness, thus increasing perceptions of individual and collective success and expectations for the future. Finally, a cohesive staff may have the knowledge of skills and concerns of teachers that can be used in persuasion (p. 166-167). In this way, collaboration that is focused on instructional improvement that advances common goals contributes to collective efficacy sources of vicarious experiences and social persuasion. In addition, Schmoker (1999) asserted that collaboration provides chances to enjoy the social and intellectual satisfactions of team effort, thus contributing to the affective state source of CTE.

\section{Further considerations and future directions}

Arguing against the existence or the positive effects and outcomes of CTE was never the intent of this article, nonetheless, examination and critique of the quantitative studies involving CTE can further support the contention that the field of education needs to reconsider the status currently ascribed to the concept. First of all, Eells (2011) attributed an average effect factor of 0.617 to collective efficacy. This was after removing an outlier study that, if included, would have resulted in an effect factor of 0.598 . Second, the effect factor of 1.57 forwarded by John Hattie included no further research than what Eells (2011) had already completed, he simply used his methods of meta-analysis to recalculate the factor (Donohoo et al., 2018).

If juxtaposing the effect factor of 1.57 against the "hinge point" of 0.4 , the number representing 1 year's growth for 1 year's input (Hattie, 2009), then it would mean that schools with high levels of CTE could expect about 4 years of growth for every year students attend that school. So, when considering this oft-cited effect size, the discrepancy between the two meta-analysis as well as what the number appears to be claiming needs to be evaluated. Attention should also be given to critiques of meta-analysis which purport that reducing evidence to a mean effect size shuts out individual events or people thereby losing complexity and value. Furthermore, it is sometimes unclear whether or not Hattie uses effect size as a comparison to a control group or a comparison of the same students before the study started (Wrigley, 2018).

Returning to the purpose of this paper, it is crucial to rethink the way we view the importance and development of CTE. Even recently, in Donohoo and Katz (2019) and DeWitt (2019), CTE continues to be treated as an attribute to be developed to drive school improvement. Although Donohoo and Katz (2019) discuss the importance of mastery in the development of CTE, the article views developing CTE as an end in itself and a way to drive school improvement. However, this article reviewed and analyzed the literature in order to create a new theory of action and be the catalyst for a new narrative in the knowledge base related to CTE. The narrative put forth in this article maintains that school processes are the most important factors in student success with collective efficacy being a result and effect of those processes that can stimulate further positive outcomes and improvement.

Figure 2 provides an alternate visual representation of the relationship between school processes and development of CTE. Although empirical testing is required to confirm the links and pathways, this diverging explanation of CTE is relevant and important because no longer is the concept a neglected construct as feared in Goddard (2001). Instead, given the current discussion surrounding CTE and the elevation the concept has received in some education circles, it may very well succumb or have already succumbed to what Eacott (2017) referred to as "the cult of the guru". 

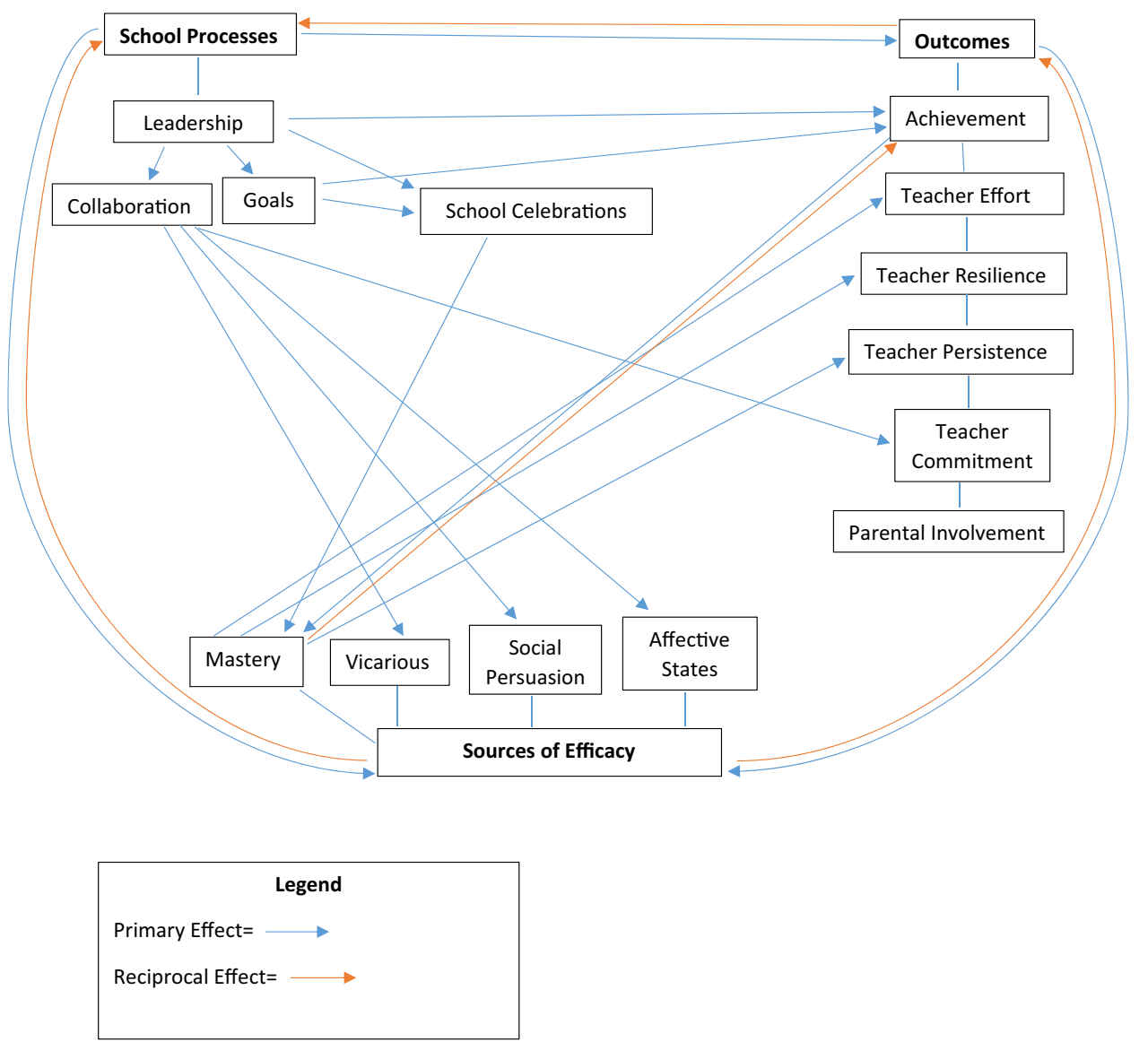

Fig. 2 Proposed model of collective efficacy development and reciprocal effects.

\section{Data availability}

All data analysed is included in the paper.

Received: 6 October 2019; Accepted: 9 December 2019;

Published online: 07 January 2020

\section{References}

Adams C, Forsyth P (2006) Proximate sources of collective teacher efficacy. J Educ Adm 44(6):625-642

Bandura A (1997) Self-efficacy: the exercise of control. W.H. Freeman and Company, New York, NY

Beauchamp L, Klassen R, Parsons J, Durksen T, Taylor L (2014) Exploring the development of teacher efficacy through professional learning experiences. Alberta Ministry of Education, Edmonton, AL

Devos G, Tuytens M, Hulpia H (2014) Teachers' organizational commitment: examining the mediating effects of distributed leadership. Am J Educ 120 (2):205-231

DeWitt P (2017) School climate: leading with collective efficacy. Corwin, Thousand Oaks, CA

DeWitt P (2019) How collective teacher efficacy develops. Educ Leadersh 76 (6):31-35

Donohoo J (2017) Collective efficacy: how educators' beliefs impact student learning. Corwin, Thousand Oaks, CA

Donohoo J (2018) Collective teacher efficacy research: productive patterns of behaviour and other positive consequences. J Educ Change 19(3):323-345

Donohoo J, Hattie J, Eells R (2018) The power of collective efficacy. Educ Leadersh 75(6):40-44

Donohoo J, Katz S (2017) When teachers believe, students achieve. Learn Professional 38(6):20-27

Donohoo J, Katz S (2019) What drives collective efficacy? Educ Leadersh 76 (6):24-29

Eacott S (2017) School leadership and the cult of the guru: the neo-Taylorism of Hattie. Sch Leadersh Manag 37(4):413-426
Eells RJ (2011) Meta-analysis of the relationship between collective teacher efficacy and student achievement. Unpublished doctoral dissertation, Loyola University of Chicago

Escobedo A (2012) Teacher perceptions of the effects of school celebrations of success on collective efficacy beliefs. Unpublished doctoral dissertation, University of Virginia

Fullan M (2005) Leadership and sustainability: system thinkers in action. Corwin Press, Thousand Oaks, CA

Goddard R (2001) Collective efficacy: a neglected construct in the study of schools and student achievement. J Educ Psychol 93(3):467-476

Goddard R, Goddard Y, Kim E, Miller R (2015) A theoretical and empirical analysis of the roles of instructional leadership, teacher collaboration, and collective efficacy beliefs in support of student learning. Am J Educ 121 (4):501-530

Goddard R, Hoy W, Hoy A (2000) Collective teacher efficacy: its meaning, measure, and impact on student achievement. Am Educ Res J 37(2):479-507

Goddard RD, Hoy WK, Hoy AW (2004) Collective efficacy beliefs: Theoretical developments, empirical evidence, and future directions. Educ Res 33(3):3-13

Hallinger P (2010) Leadership for learning: lessons from 40 years of empirical research. J Educ Adm 49(2):125-142

Hattie J (2009) Visible learning: a synthesis of over 800 meta-analyses relating to achievement. Routledge, London

Klassen R (2010) Teacher stress: the mediating role of collective efficacy beliefs. J Educ Res 103(5):342-350

Leithwood K, Louis K, Anderson S, Wahlstrom K, Mascall B, Gordon M, Thomas E, Jantzi D, Knapp M (2012) Linking leadership to student learning, 1st edn. Jossey-Bass/Wile, San Francisco, CA

Leithwood K, Patten S, Jantzi D (2010) Testing a conception of how school leadership influences student learning. Educ Adm Q 46(5):671-706

Planche B (2019) Harnessing the power of the collective. Canadian Association of Principals. Retrieved from https://cdnprincipals.com/harnessing-the-powerof-the-collective/

Robinson V (2011) Student-centered leadership. Jossey-Bass, San Francisco, CA

Ross J, Gray P (2006) Transformational leadership and teacher commitment to organizational values: The mediating effects of collective teacher efficacy. Sch Effectiveness Sch Improvement 17(2):179-199 
Ross J, Hogaboam-Gray A, Gray P (2004) Prior student achievement, collaborative school processes, and collective teacher efficacy. Leadersh Policy Sch 3 (3):163-188

Schmoker M (1999) Results: The key to continuous improvement, 2nd edn. ASCD, Alexandria, VA

Tschannen-Moran M, Barr M (2004) Fostering student learning: the relationship of collective teacher efficacy and student achievement. Leadersh Policy Sch 3 (3):189-209

Wrigley T (2018) The power of 'evidence': reliable science or a set of blunt tools? Br Educ Res J 44(3):359-376

\section{Competing interests}

The author declares no competing interests.

\section{Additional information}

Correspondence and requests for materials should be addressed to T.J.H.

Reprints and permission information is available at http://www.nature.com/reprints
Publisher's note Springer Nature remains neutral with regard to jurisdictional claims in published maps and institutional affiliations.

\section{(c) (i)}

Open Access This article is licensed under a Creative Commons Attribution 4.0 International License, which permits use, sharing, adaptation, distribution and reproduction in any medium or format, as long as you give appropriate credit to the original author(s) and the source, provide a link to the Creative Commons license, and indicate if changes were made. The images or other third party material in this article are included in the article's Creative Commons license, unles indicated otherwise in a credit line to the material. If material is not included in the article's Creative Commons license and your intended use is not permitted by statutory regulation or exceeds the permitted use, you will need to obtain permission directly from the copyright holder. To view a copy of this license, visit http://creativecommons.org/ licenses/by/4.0/.

(C) The Author(s) 2020 